\title{
The Management of Park Equipment and Machinery Used in the Construction Industry and Housing Sector
}

\author{
Rustam Khayrullin ${ }^{l, *}$, Pavel Marichev ${ }^{2}$ \\ ${ }^{1}$ Doctor of Physics and Mathematics, Professor, Moscow State University of Civil Engineering, \\ Moscow, Russia \\ ${ }^{2} \mathrm{Ph} . \mathrm{D}$, Head of Department, Main Scientific Metrological Center, Mytishchi, Moscow region, Russia
}

\begin{abstract}
The mathematical model was created, applicable to elaboration of options of development of a park of equipment and machinery used in construction industry, housing and utility management. The model based on solving the linear programming problem by means of simplex method. The mathematical model allows develop the rational plans and quasi optimal plans. The model is based on the created in the article the financial management algorithms of procurement and of repairs of equipment and machinery. The algorithms allow to take into account joint consideration of indicators of modernity and operability of equipment and machinery. The basic model is developed. The model is included into the automated planning system. It is used for planning and preparation of proposals of draft policy documents for development of park devices, equipment and machinery.
\end{abstract}

\section{Introduction}

The problem of management of park of industrial equipment, computer facilities and control - measuring devices is an urgent practical task in mechanical engineering, industry and information technologies [1-6]. In the construction and housing sectors used a wide variety of equipment and machinery (EM): lifting mechanisms, water meters, heat meters, air-conditioners and so on. So the problem of management of park of equipment and machinery (PEM), undoubtedly, is an urgent practical task in the sphere of a construction and housing sector.

To assess the level of technical excellence and technical condition of the PEM and some types of EM it is proposed to use an indicator of modernity and an indicator of operability. Maintenance of indicators at the required level is possible at the expense of the balanced combination of purchases and repairs of some types and samples of EM.

\section{Model of the modernity and operability}

We introduce the notation:

$\mathrm{N}$ - total number of samples of EM,

$\mathrm{N}_{\mathrm{op}}$ - number of operating samples of EM at the initial time of planning, 
$\mathrm{N}_{\mathrm{mo}}$ - number of modern samples of $\mathrm{EM}$ at the initial time of planning,

$\mathrm{N}_{\mathrm{z}}$ - number of the purchases,

$\mathrm{N}_{\mathrm{p}}$ - number of repairs,

$\mathrm{S}_{\mathrm{z}}, \mathrm{S}_{\mathrm{p}}$ - the average price of purchase and repair,

$\mathrm{S}$ - amount of the funds allocated for purchase and repair together,

$\mathrm{k}_{1}, \mathrm{k}_{2}$ - operability coefficients for modern and outdated samples of EM, $0<\mathrm{k}_{1} \leq \mathrm{k}_{2}<1$.

Modernity indicator:

$$
P_{\text {mod }}=\frac{\left(N_{m o}+N_{z}\right)}{N}
$$

Operability indicator:

$$
P_{o p b}=\frac{N_{o p}}{N}=\frac{k_{1} N_{m o}+k_{2}\left(N-N_{m o}\right)+N_{z}+N_{p}}{N}
$$

Amounts of financing for purchases and repairs:

$$
S=N_{z} S_{z}+N_{p} S_{p}
$$

It is supposed that the purchased sample of EM is modern and operable and remains to this state during the period under review.

If to express from (1) and (3) variables of $N_{z}, N_{p}$ and to substitute them in (2), then we will receive linear relationship between indicators:

$$
P_{\text {opb }}=a P_{\text {mod }}+b
$$

Where

$$
\left\{\begin{array}{c}
a=1-\frac{S_{z}}{S_{p}} \\
b=\frac{S}{S_{p} N}+\frac{N_{m o}\left(k_{1}-k_{2}-1+\frac{S_{z}}{S_{p}}\right.}{N}+k_{2} \\
a<0, b>0
\end{array}\right.
$$

Therefore:

1. In case of the fixed amount of financing $S$ and increase the indicator of the modernity $P_{\text {mod }}$, the indicator of operability $P_{o p b}$ will decrease and vice versa,

2. In case of increase $S$ and the fixed value of $P_{\text {mod }}$, the indicator of operability $P_{o p b}$ will increase,

3. In case of increase $S$ and the fixed value of $P_{o p b}$, the indicator of modernity $P_{\text {mod }}$ will increase.

\section{A problem of maximum the indicator of the modernity of PEM in case of restrictions for indicators of operability and the amount of financing}

It is required to maximize the indicator of modernity of PEM:

$$
\frac{1}{I} \sum_{i=1}^{I} P_{\text {mod }}^{i}=\frac{1}{I} \sum_{i=1}^{I} \frac{N_{m o}^{i}+N_{z}^{i}}{N^{i}} \rightarrow \max
$$

Under restriction from above for the total amount of financing directed to purchase of modern samples and repair of defective modern and defective outdated samples of EM: 


$$
\sum_{i=1}^{I} N_{z}^{i} S_{z}^{i}+\sum_{i=1}^{I} N_{p m n}^{i} S_{p}^{i}+\sum_{i=1}^{I} N_{p y n}^{i} S_{p}^{i} \leq S
$$

And condition that operability of each type of EM is limited from below and from above:

$$
k_{\text {min }}^{i} N^{i} \leq N_{\text {opo }}^{i}+N_{z}^{i}+N_{\text {pmn }}^{i}+N_{\text {pyn }}^{i} \leq k_{\text {max }}^{i} N^{i}, i=1,2, \ldots, I
$$

We assumed that number of purchases and repairs cannot be negative:

$$
N_{z}^{i} \geq 0, N_{m n o}^{i} \geq N_{p m n}^{i} \geq 0, N_{p y n}^{i} \geq 0, i=1,2, \ldots, I
$$

Here the upper index means parameter belonging to the corresponding type of EM;

$I$ - number of types of EM;

$N_{\text {opo }}^{i}$ - number of operable samples;

$N_{m n o}^{i}$ - number of modern defective samples;

$k_{\min }^{i}, k_{\max }^{i}$ - restrictions from below and from above on a operability indicator;

$N_{p m n}^{i}, N_{p y n}^{i}$ - the number of repairs of modern defective samples and outdated defective samples of EM correspondingly.

The problem formulated in this chapter's is a standard integer linear programming problem (LPP) in unknowns: $N_{z}^{i}, N_{p m n}^{i}, N_{p y n}^{i}$ [7], where $N_{p}^{i}=N_{p m n}^{i}+N_{p y n}^{i}$. It solve by means of simplex method [7].

\section{The results of the calculation}

Calculations were performed with the following data values:

$I=3 ; N^{1}=41503 ; N^{2}=24000 ; N^{3}=52000 ; N_{m o}^{1}=8469 ; N_{m o}^{2}=2300 ;$

$N_{m o}^{3}=21000 ; N_{\text {opo }}^{1}=23365 ; N_{\text {opo }}^{2}=12300 ; N_{\text {opo }}^{3}=24000 ; N_{m n o}^{1}=847$;

$N_{\text {mno }}^{2}=200 ; N_{\text {mno }}^{3}=2000 ; k_{\text {min }}^{1}=k_{\min }^{2}=k_{\min }^{3}=0.8$;

$k_{\max }^{1}=k_{\max }^{2}=k_{\max }^{3}=0.95-1.00 ; S_{z}^{1}=0.55 ; S_{z}^{2}=1.0 ; S_{z}^{3}=0.14 ; S_{p}^{1}=0.055$;

$S_{p}^{2}=0.20 ; S_{p}^{3}=0.028$

Calculations were performed for different values of $S, k_{\text {max }}^{i}, i=1,2,3$.

In Table 1 shows the indicators of modernity and operability. The table shows that in case of the small amounts of financing: $S<S_{1}$ all funds should be allocated for repair of EM (on achievement by indicators of operability of each of types of EM of the admissible lower bound). The corresponding LPP has no solution.

At $S=S_{1}$ indicators of operability of all types of EM reaches to the lower admissible bound of $80 \%$ due to repairs.

At $S_{1}<S<S_{2}$ a condition of operability are carried out strictly on the lower bound, and funds redistribution with increase in purchases and reduction of repairs of EM of the third type (EM -3) is made.

At $S=S_{2}$ amount of the funds allocated for repair decreases up to the size necessary for repair of the available 2000 modern defective samples and there is the modernity indicator exit on EM -3 to the level of $95 \%$.

At $S_{2}<S<S_{3}$ means go for purchase of EM-1, and the funds allocated for repairs of EM-1 decrease. 
At $S=S_{3}$ the funds allocated for repairs of EM-1 decrease up to the size necessary for repair of the available 847 modern defective sample, and there is a modernity indicator exit on EM-1 to the level of $95 \%$.

At $S_{3}<S<S_{4}$ means the funds allocated for repair of EM-2 decrease go for purchase of EM -2 .

At $S=S_{4}$ the indicator of operability of EM-2 reaches to the level of $95 \%$. The funds allocated for repair decreased up to the size necessary for repair of the outdated 200 available modern samples of EM-2.

Since the number of samples of different types of PEM and the corresponding values of purchases and repairs are represented by numbers of a different order of magnitude, then for ease of perception of information in Table 2 shows the amount of funds for purchase and repairs.

Table 1. Results of calculations indicators for operability range from $80 \%$ to $95 \%$.

\begin{tabular}{|c|c|c|c|c|c|c|}
\hline \multirow{2}{*}{$\begin{array}{l}\text { Notatio } \\
\text { n }\end{array}$} & \multirow[b]{2}{*}{ Funds } & \multirow[b]{2}{*}{ Indicators } & \multicolumn{3}{|c|}{ Performance indicators } & \multirow{2}{*}{ Criterion } \\
\hline & & & EM-1 & EM-2 & EM-3 & \\
\hline & \multirow{2}{*}{1000} & $P_{\text {mod }}$ & $\begin{array}{c}\text { No } \\
\text { solution }\end{array}$ & $\begin{array}{c}\text { No } \\
\text { solution }\end{array}$ & $\begin{array}{c}\text { No } \\
\text { solution }\end{array}$ & \multirow{2}{*}{0} \\
\hline & & $P_{o p b}$ & $\begin{array}{c}\text { No } \\
\text { solution }\end{array}$ & $\begin{array}{c}\text { No } \\
\text { solution }\end{array}$ & $\begin{array}{c}\text { No } \\
\text { solution }\end{array}$ & \\
\hline \multirow{4}{*}{$S_{1}$} & \multirow{2}{*}{1856} & $P_{\text {mod }}$ & 0.22 & 0.1 & 0.44 & \multirow{2}{*}{0.253} \\
\hline & & $P_{o p b}$ & 0.8 & 0.8 & 0.8 & \\
\hline & \multirow{2}{*}{4000} & $P_{\text {mod }}$ & 0.22 & 0.1 & 0.8 & \multirow{2}{*}{0.373} \\
\hline & & $P_{o p b}$ & 0.8 & 0.8 & 0.85 & \\
\hline \multirow{4}{*}{$S_{2}$} & \multirow{2}{*}{4695} & $P_{\text {mod }}$ & 0.22 & 0.1 & 0.89 & \multirow{2}{*}{0.403} \\
\hline & & $P_{o p b}$ & 0.8 & 0.8 & 0.95 & \\
\hline & \multirow{2}{*}{8000} & $P_{\text {mod }}$ & 0.39 & 0.1 & 0.89 & \multirow{2}{*}{0.460} \\
\hline & & $P_{o p b}$ & 0.8 & 0.8 & 0.95 & \\
\hline & \multirow{2}{*}{12000} & $P_{\text {mod }}$ & 0.57 & 0.1 & 0.89 & \multirow{2}{*}{0.520} \\
\hline & & $P_{o p b}$ & 0.93 & 0.8 & 0.95 & \\
\hline \multirow{4}{*}{$S_{3}$} & \multirow{2}{*}{12569} & $P_{\text {mod }}$ & 0.59 & 0.1 & 0.89 & \multirow{2}{*}{0.527} \\
\hline & & $P_{o p b}$ & 0.95 & 0.8 & 0.95 & \\
\hline & \multirow{2}{*}{16000} & $P_{\text {mod }}$ & 0.59 & 0.28 & 0.89 & \multirow{2}{*}{0.587} \\
\hline & & $P_{o p b}$ & 0.95 & 0.81 & 0.95 & \\
\hline \multirow{2}{*}{$S_{4}$} & \multirow{2}{*}{19297} & $P_{\text {mod }}$ & 0.59 & 0.42 & 0.89 & \multirow{2}{*}{0.633} \\
\hline & & $P_{o p b}$ & 0.95 & 0.95 & 0.95 & \\
\hline
\end{tabular}

The general indicator of the modernity of PEM constitutes 0.63 .

Note that further increase in level of the modernity for each type of EM and for PEM at all in general is possible only by means of the purchases some number of modern 
operable samples with replacement of outdated operable sample in the sequence of EM 3, EM -1, EM-2.

In the Fig. 1 shows changes of an indicator of the modernity of PEM depending on amount of financing in case of restrictions for an indicator of operability of $80 \%-95 \%$ and $80 \%-100 \%$ are provided. Let's note that in case $S=22003$ it is possible to increase an indicator of the modernity of PEM to level 0,68 .

\section{Stages of management of funds allocated for PEM development}

On the basis of the analysis of calculations results it is possible to allocate the following consecutive stages of financing management for development of midterm and long- term plans:

Table 2. Results of calculations of founds for indicator operability range from $80 \%$ to $95 \%$.

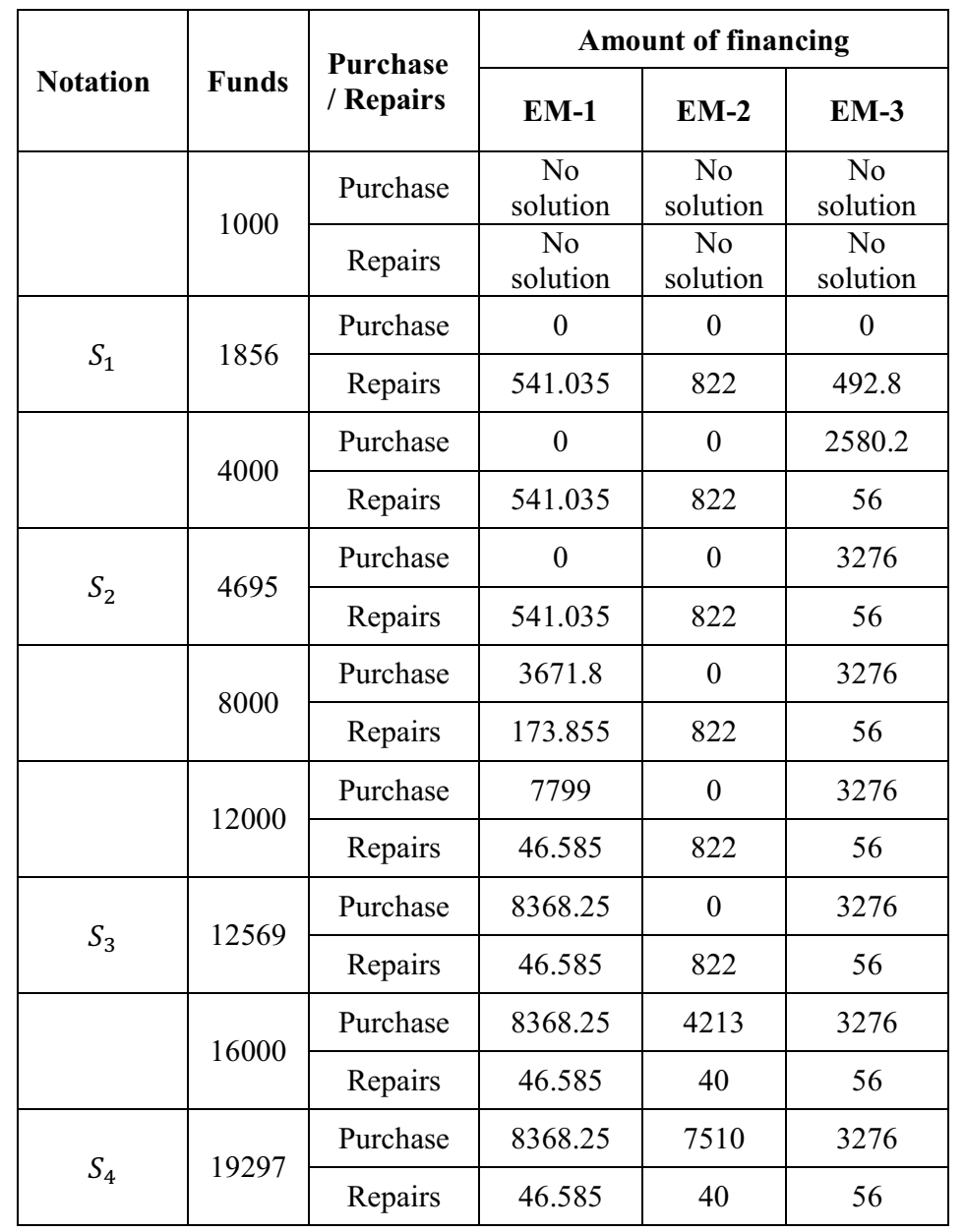

1. Funds shall be allocated only for repairs both modern defective and outdated defective sample of EM in sufficient quantity to achieve the lower bound on a operability indicator on all types of EM in the sequence: EM-3, EM-1, EM-2. 
2. Funds shall be re-allocated from repairs on purchases of EM, at the same time funds for repairs decrease to the amount sufficient for repair of modern defective samples. At first restriction on a operability indicator on the lower bound is maintained. Then the indicator of operability increases to the upper bound. The clause is implemented for all types of EM in the sequence: EM -3, EM-1, EM-2. The indicator of the modernity increases up to the target objective.

Note that if the amount of financing is rather big, and financial risks are small, then in point 1 it is reasonable to direct funds only for repairs of modern defective samples and purchase of modern operable samples. Then proceed to clause 2.

\section{Conclusion}

The provided model shall be applied for development of mid-term and long- term plans of purchases and repairs (and financial plans too) [1]. At each planning interval the following shall be performed:

1. Clarification of initial data as of the commencement planning time,

2. Solution of basic LPP,

3. Adjustment of initial data using the model of modernity and operability,

4. Clarification of initial data using the model of non-availability of funding and impossibility of implementation of the required development option [1].

The described model is included into the automated PEM management system. It used for creation of development plans of PEM, development of refurbishment strategy, procurement write-off, repair strategy and so on. It used for middle - term planning and long-term planning. It can be used for simulation of PEM development in case of limited and unlimited funding.

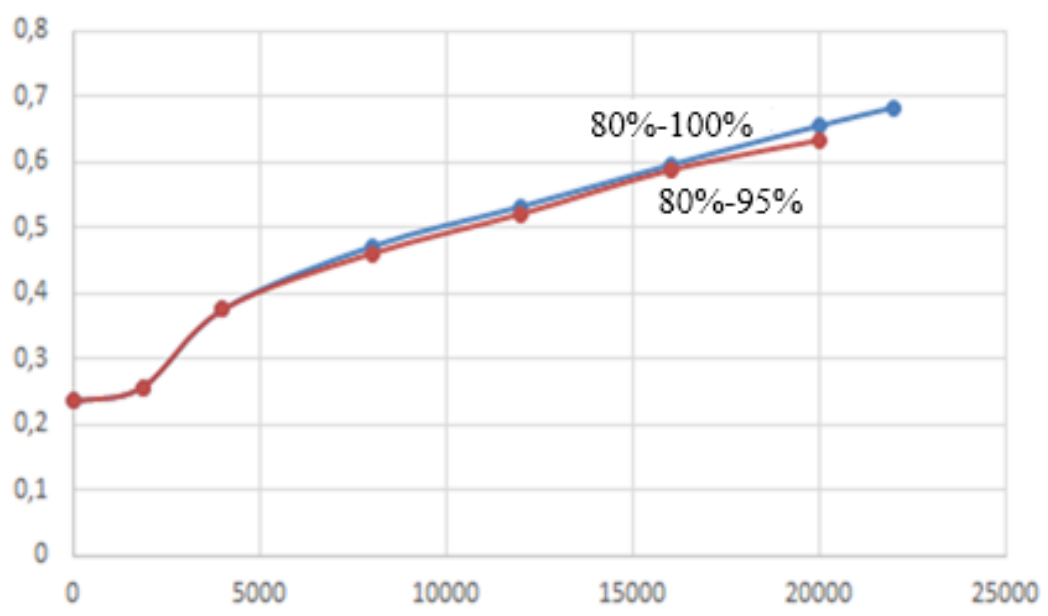

Figure 1. Indicator of the modernity depends on the amount of found.

To obtain results suitable for practical application the of generally LPP solution is sufficient [7]. Solving the LPP using a computer takes less 1 second. Solving an integer values linear programming problem takes $3-4$ seconds.

\section{References}

1. V.M. Burenok, R.N. Pogrebnyak, A.R. Skotnikov, Mashinostroenie, 1 (2010)

2. V.N. Burkov, G.S. Javakhadze, Russian Academy of Science, 69 (1996) 
3. I.S. Lifanov, N.G. Sherstyukov, Moscow, 225 (1979)

4. R.Z. Akberdin, Mashinostroenie, 184 (1987)

5. R.Z. Khayrullin, Scientific review, 10 (2016)

6. A. Mas-Collel, M.D. Whinston, J.R. Green, Univ. Press, 981 (1995)

7. R.Z. Khayrullin, Vestnik MGSU, 8 (2013) 